مجلة كلية التربية الرياضية - جامعة بغداد ** المجلد الثلاثون ** العدد الثاني ** لسنة

\title{
علاقة بعض القدرات البدنية بدقة مهارة الضربة الأرضية الأمامية لائ لاعبي الإسكوش
}

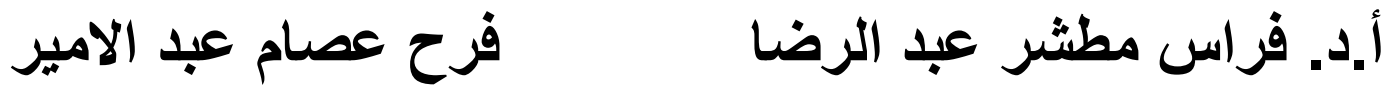

\section{D $1 \leqslant \mu q$}

مستخلص البحث باللغة العربية.

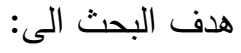

التعرف على نوع العلاقة بين بعض القدرات البدنية (القوة والمرونة) بدقة مهارة الضربة الأرضية الأمامية لدى لاعبي الاسكواش.

وقد أستخدم الباحثان المنهج الوصفي بأسلوب العلاقات الأرتباطية، اما عينة البحث فقد تم أختيارها بالطريقة

$$
\begin{aligned}
& \text { العمدية وتمنلت ب(6) لاعبين من لاعبي أندية العراق للدوري الممتاز في لعبة الإسكواش } \\
& \text { وكانت أهم الأستنتاجات التي توصلت لها الباحثان: } \\
& \text { تبين ان هنالك ضعف قي القوة والمرونة والدقة لدى اللاعبين. }
\end{aligned}
$$

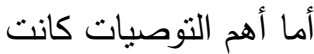

$$
\begin{aligned}
& \text { • أعداد منهاج تدريبي لتطوير دقة الأداء المهاري. } \\
& \text { هنالك ضعف لدى اللاعبين في القدرات البدنية (القوة والمرونة). }
\end{aligned}
$$

\section{Abstract. \\ Correlation Relationship Between Physical Abilities And The Accuracy Of Forehand Shot In Squash}

The researcher aimed at identifying the type of relationship between physical abilities (strength and flexibility) with the accuracy of forehand shot in squash. 


\section{مجلة كلية التربية الرياضية - جامعة بغداد ** المجلد الثلاثون * العدد الثاني ** لسنة \\ $r+11$}

The researchers used the descriptive method. The subjects were (6) squash players from the national league. The data was collected and treated using proper statistical operations to conclude that there is a correlation relationship between the training program physical abilities (strength and flexibility). In addition to that there are weaknesses in the physical abilities of players in strength and flexibility.

The researchers recommended deigning a training program for developing the accuracy of motor performance.

Keywords: correlation, accuracy, physical abilities, squash.

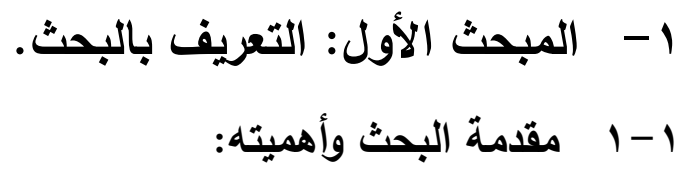

أن التطور الحاصل في المجال الرياضي جاء نتيجة الدراسات والبحوث العلمية لمعرفة نقاط القوة والضعف

لاى اللاعبين ومحاولة تقليل الأخطاء وخاصة في جانب الأداء المهاري لاى اللاعبين في لعب الإسكواش كونها أحد اللألعاب السريعة التي تتطلب قدرات بدنية عالية وخاصة القوة والمرونة لاى اللاعب ليتمكن من ضرب الرة بدقة عالية طيلة فترة المباراة.

ومما تقدم تكمن أهمية البحث في دراسة علاقة أرتباط بين بعض القدرات البدنية بدقة مهارة الضربة الأرضية الأمامية لدى لاعبي الإسكواش.

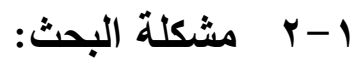

ان احد الجوانب المهمة التي يجب ان براعيها لاعب الإسكواش من أجل الفوز في المباراة هي الدقة ومن

المتعارف عليه ان لعبة الإسكواش لعبة سريعه لذلك تتطلب قدرات بدنية عالية حتى يسنطيع اللأعب ان يحافظ على الدقة العالية على طول فترة المباراة، ولكون الباحثان ومن خلال خبرة الباحثان الميدانية كونها لاعب منتخب الكلية وأحد حكام الدرجة الأولى في لعبة الإسكواش، ومتابعة العديد من مباريات الدوري العراقي الممناز لكرة الإسكواش، لاحظت ان هنالك ضعف في القدرات البدنية لاى اللاعبين ولاسيما القوة والمرنة لدى لاعبي الأسكواش مما تؤثر على الدقة اثثاء المباريات خاصنا، لذلك أرتات الباحثة في الخوض في دراسة علاقة أرتباط بعض القرات البدنية بدقة مهارة الضربة الأرضية الأمامية لدى لاعبي الإنكواش.

年

التعرف على نوع العلاقة بين بعض القدرات البدنية (القوة والمرونة) بدقة مهارة الضربة الأرضية الأمامبة لدى

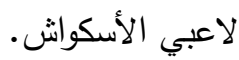


مجلة كلية التربية الرياضية - جامعة بغداد ** المجلا الثلاثون* العدد الثاني ** لسنة

(

1-ـ - المجال البشري: لاعبي أندية العراق للدوري الممتاز في لعبة الإسكواش وعددهم (6) لاعبين للموسم (-2018

1- - - المجال الزماني: الفترة الزمينة من 2018/1/24 ولغاية 2018/2/6. 1-ـ - المجال المكاني: ملاعب للإسكواش في كلية التربية البدنية علوم الرياضة / جامعة بغداد

r - المبحث الثاني: منهج البحث واجراعاته الميدانية. r

أستخدمت الباحثة المنهج الوصفي بأسلوب العلاقات الأرتباطية.

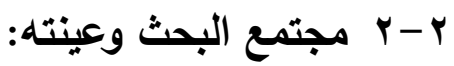

أن من اهم الأمور العملية التي يجب على الباحثان ان تراعيها هي الحصول على عينة تمثل المجتمع

تمنيلا حقيقا، أذ تمنل مجتمع البحث على الدوري العراقي الممتاز للإسكواش لسنة (2017-2018) والذي تكون من (40) لاعبا، اما عينة البحث فقد تمت أختبارها بالطريقة العدية والبالغ عددهم (6) لاعبين الذي منلوا المنتخب العراقي في مناسبات عديده، اذ متلو نسبة (15\%) من مجمتع البحث.

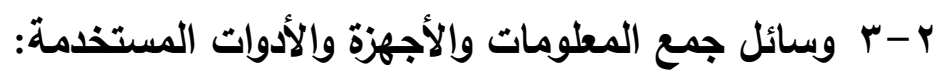

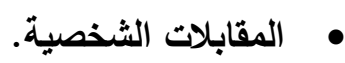
• المصادر العربية والاجنبية. • الاختبارات البدنية. • استمارات جمع وتفريغ البيانات. • شبكة المعلومات العالمية (Internet). • الأجهزة والأدوات المستخدمة في البحث: • جهاز داينوميتر لقياس القوة العضلية لابتوب (DEEL) صينية الصنع عدد(1) (5000 Series) 15 (Inspiron

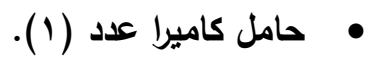
•ملعب الإسكواش قانوني في كلية التربية البلنية وعلوم الرياضة / جامعة بغداد - الجادرية. • شواخص بلاستيكية عدد ( • (1). 
مجلة كلية التربية الرياضية - جامعة بغداد ** المجلد الثلاثون ** العدد الثاني * لسنة $r \cdot 1 \Lambda$

$$
\begin{aligned}
& \text { • اقراص ليزرية (CD)عدد (10). } \\
& \text { • صافرات عدد (r). } \\
& \text { • شريط قياس. } \\
& \text { • شريط لاصث. } \\
& \text { • مسطبه. }
\end{aligned}
$$

\section{r}

أن أستخدام هذا النوع من البحوث الا وهي البحوث الوصفية غالبا ما يتطلب العمل على مجموعة من الأختبارات وذلك لقياس الصفة القدرات والمهارات المطلوبة دراساتها، وبعد أخذ أراء الخبراء والمختصين في هذا المجال نم تحديد الأختبارات التي سوف تستخدمها الباحثنان.

$$
\text { م اختبارات القوة: }
$$

اولا: اختبار قياس قوة عضلات الرجلين: (1: ه ؟)

$$
\text { • اسم الاختبار : اختبار قوة عضلات الرجلين. }
$$$$
\text { • الهذف من الاختبار: قياس قوة عضلات الرجلين. }
$$

• الأدوات المستخدمة: جهاز الدينامومنز لقياس قوة عضلات الرجلين (Dynamometer).

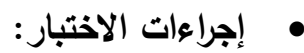

ل قبل الأداء يقوم الباحث بشرح طريقة الأداء الصحيح أمام اللاعبين، مع إعطاء نموذج صحيح أمام

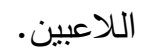

يقف اللاعب على الجهاز واضعاً قدميه في المكان المخصص لذلك، بحيث يقوم بثثي الركبتين، والظهر

$$
\text { يكون منتصب ونظر اللاعب إلى الأمام بالاتجاه الأفقي. }
$$

يقوم اللاعب بمسك المقبض المخصص بيديه بالقبض عليه من الأمام بكلتا يديه.

ل وعندما يكون اللاعب جاهزا يبدأ بالسحب مستخدما أقصى قوة لديه، وعندها يقوم المحكم بقراءة المؤشر

$$
\text { وتسجيل الرقم الذي حصل عليه اللاعب. }
$$

طريقة التسجيل: يعطى اللاعب ثلاث محاولات بينهما فترة راحة كافية وتعتمد له أعلى المحاولات.

ثانيا: اختبار الوثب العريض من الثبات.(2:9)

$$
\text { اسم الاختبار : الوثب العريض من الثبات. }
$$

الهُف من الاختبار : قياس قوة عضلات الرجلين. 
مجلة كلية التربية الرياضية - جامعة بغداد ** المجلد الثثلاثون * العدد الثاني ** لسنة Y. IN

• الأدوات المستخدمة: ارض مستوية لا تعرض الفرد للانزلاق، شريط قياس،يرسم على الارض خط للبداية. • إجراءات الاختبار: يقف المختبر خلف خط البداية والقدمان منباعدتان قليلا والذراعان عاليا، تمرجح الذراعان اماما اسفل خلفا مع ثي الركبتين نصفا وميل الجذع اماما حتى يصل الى ما يشبه وضع البدء بالسباحة، تمرجح الذراعان اماما بقوة مع مد الرجلين على امتداد الجذع ودفع الارض بالقدمين بقوة من محاولة الوثب باء اماما ابعد مسافة ممكنة •طريقة التسجيل: بيجل المختبر محاولنان ويسجل له افضلهما. O اختبارات المرونة:

اولا: اختبار ثني الجذع الى الامام والاسفل من الوقوف على الصندوق. (67:3) اسم الاختبار: ثثي الجذع إلى ألامام والأسفل من الوقوف على الصندوق. الهُف من الاختبار: قياس مرونة العمود الفقري وعضلات خلف الفخذ. الأدوات المستخدمة: مسطرة مدرجة، صندوق مثبت على الأرض.

إجراءات الاختبار: يقف المختبر على الصندوق مرتفع مع ضم القدمين ومد الركبنين كاملاً ويثثي الجذع إلى الأمام والأسفل محاولاً تمرير أطراف أصابع اليدين في مستوى اقل من سطح الصندوق والثبات في هذا الوضع لحساب القراءة بالسنتمتر ، بالسالب أو بالموجب وذلك عن مستوى سطح الصندوق.

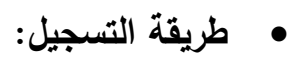
ل إذا لم تصل أطراف الأصابع مستوى سطح الصندوق كانت القراءة بالسالب وبالسنتمتر . ل إذا تخطت مستوى السطح إلى الأسفل كانت القراءة بالموجب وبالسنتمتر . التوجيهات: يجب عدم ثثي الركبنين.

ثانيا: اختبار مرونة اسفل الظهر وعضلات الفخذ الخلفية.(A:4) • اسم الاختبار : مرونة اسفل الظهر وعضلات الفخذ الخلفية. الههف من الاختبار : قياس مرونة اسفل الظهر وعضلات الفخذ الخلفية. الأدوات المستخدمة: مقعد وطاولة مدرجة او مصطبة مع مسطرة (مدرجة). إجراءات الاختبار (التوجيهات): ل السماح للاعبين الاحماء عن طريق الجري. ل وضع البداية يكون بالجلوس على الأرض مع إزالة ونزع الأحذية، الاقدام مبسوطة ضد الطاولة، والساقين تكون باستقامة واحدة. ل يجب على اللاعب الوصول إلى الأمام ودفع أصابعه على طول الطاولة إلى أقصى حد ممكن دون رفع ركبنتيه. 
$\checkmark$ ل المسافة من حافة الاصبع إلى حافة الطاولة او المصطبة يمثل النتيجة للشخص.

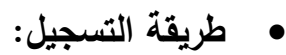

ل بما أن الطاولة "الدرجة" تحتوي على 10 سم، فإن الثخص الذي يصل إلى • (1 سم منجاوزاً أصابع قدميه تكون نتيجته ويسجل له ب سم.

ل اللاعبين يكملون ما لا يقل عن ثلاث محاولات ولكن قد تستمر إذا كانوا لا يزالون بحاجة الى التحسين. يتم تسجيل أفضل المحاولات للثخص المختبر •

o

• أسم الأختبار : قياس الدقة للضربة الأمامية المستقيمة في الأسكواش.(66:5) • أجراءات الأختبار: يجري الأختبار في ملعب نظامي للأسكواش بأستخدام مضارب إسكواش وكرات إسكواش وأستمارة نسجيل، أذ يقسم الجزء الخلفي من الجهة اليمنى للملعب خلف مربع الأرسال الى (4) مجالات متساوية، والبعد بين مجال وأخر (70)سم، كذلك برسم على الحائط الأمامي الأيمن (4) مجلات المسافة ما بين كل مجال وأخر (25) سم. مواصفات الأداء: ترسل الكرة الى اللاعب بواسطة الزميل، ويبدأ اللاعب المختبر بتتفيذ مهارة الضربة الأرضية الأمامية بشرط ان تلعب داخل المجالات على الحائط الأمامي وتصل الى الخلف من مربع الأرسال

$$
\text { الأيمن الى المجالات المحددة وتعطي للاعب (10) محاولات. }
$$

تسجيل النقاط: تحسب النقاط لكل ضربة صحيحة وفق الأتي: جدول (3)

(4) نقاط اذا لمست الكرة المجال (4)+ (4) نقاط اذا لمست الكرة مجال رقم (4) على الجدار. (3) نقاط اذا لمست الكرة المجال رقم (3) + (3) نقاط اذا لمست الكرة مجال رقم (3) على الجدار .

ل نقطتان اذا لمست الكرة المجال رقم (2) + نقطتان اذا لمست الكرة مجال رقم (2) على الجدار. ل نقطة واحدة اذا لمست الكرة المجال رقم (1) + نقطة واحدة اذا لمست الكرة مجال رقم (1) على الجدار .

$$
\begin{aligned}
& \text { ل صفر اذا كانت الكرة خارج الحدود المرسومة. } \\
& \checkmark \text { أقصى درجة يمكن الحصول عليها هي (80) درجة. }
\end{aligned}
$$

r - ب التجرية الأستطلاعية:

قام الباحثان بأجراء التجربة الأستطلاعية على لاعبين أثنين من أندية الدوري العراقي الممتاز وهم من خارج عينة البحث وقد أستمرت الأختبارات ليومين، وأجرى الباحثان الأختبارات في اليوم الأول أختبارات القوة والمرونة، في يوم الأربعاء المصادف 2018/1/24 في تمام الساعة الرابعة عصرا، اما في اليوم الثاني قام الباحثان بأجراء الأختبار المهاري في يوم الخميس المصادف 2018/1/25 في تمام الرابعة عصرا، وقد نم أجراء الأختبارات على ملاعب كلية التربية البدنية وعلوم الرياضة - جامعة بغداد، وكان الغرص من التجربة الأستطلاعية هو معرفة مدى صلاحية الأختبارات وملائمة الأختبارات لعينة البحث ومعرفة مدى صلاحية الأجزة والأدوات المستخدمة، ومعرفة كفاءة فريق 
مجلة كلية التربية الرياضية - جامعة بغداد ** المجلد الثلاثون ** العدد الثاني ** لسنة r. IN

العمل المساعد، كما المعوقات والصعوبات التي قد تواجه الباحثان أثناء اداء التجربة الرئيسية وتلافي هذه المعوقات والصعوبات.

ץ - ب التجربة الرئيسة:

قام الباحثان بأختبار عينة البحث على مدى ثلاث أيام على ملاعب كلية التربية البدنية وعلوم الرياضة -

جامعة بغداد أذ تم أجراء أختبارات القوة في يوم الثناثاء المصادف 2018/1/30 في تمام الساعة الرابعة عصرا ، ومن ثم قامت الباحثان بأجراء أختبارات المرونة في يوم السبت المصادف 2018/2/3 في تمام الساعة الرابعة عصرا وبعد ذلك قامت الباحثان بأجراء الأختبار المهاري على عينة البحث في بوم الثلاثاء المصادف 2018/2/6 في تمام الساعة الرابعة عصار .

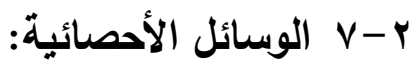

لقد أستخدم الباحثان الحقيبة الأحصائية ال (SPSS) لمعالجة البيانات أحصائيا. وأستخدم الباحثان

المعاملات الأحصائية الثالية:

$$
\text { • • الاتحراف المعامل الارتباط (بيرسون). }
$$

r- المبحث الثالث: عرض النتائج ومناقشتها:

ץ-1 عرض الأوساط الحسابية والأنحرافات المعيارية ومعمل الأرتباط (بيرسن) ومستوى الالالة ونوع الفرق للأختبارات البدنية وعلاقتها بدقة الضربة الأمامية الأرضية في الإسكواش:

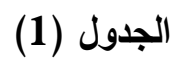

\begin{tabular}{|c|c|c|c|c|c|}
\hline نوع العلاقة & نسبة الخطأ & معامل الأرتباط & $\varepsilon^{ \pm}$ & سَ & اسم الأختبار \\
\hline غير معنوي & 0.85 & 0.09 & 12 & 220 & الوثب العريض من الثبات \\
\hline غير معنوي & 0.64 & 0.24 & 9.35 & 217 & قياس قوة عضلات الرجل \\
\hline غير معنوي & 0.96 & 0.02 & 1.21 & 15.66 & مرونة أسف الظهر وعضلات الفخذ الخلفية \\
\hline غير معنوي & 0.96 & 0.43 & 1.04 & 12.5 & ثلى الصنى الجذع الى الأمام والأسفل من الوقوف \\
\hline
\end{tabular}

الأوساط الحسابية والأنحرافات المعيارية ومعامل الأرتباط (بيرسن) ومستوى الدلالة ونوع الفرق للأختبارات البدنية

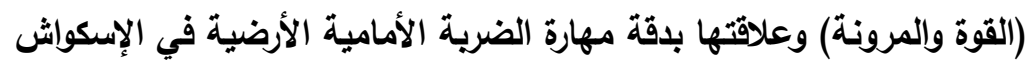

نسبة الخطأ معنوي $\geq(0.05)$ 
r-r مناقثة النتائج للأختبارات البدنية (القوة والمرونة):

أظهرت النتائج ان هنالك علاقة ارتباط ضعيفة بين القدرات البدنية (القوة والمرونة) بدقة الضربة الأمامية المستقيمة في الأسكواش وتعزوا الباحثان ذلك نتيجة الضعف في القدرات البدنية وخاصنا (القوة والمرونة) لدى اللاعبين مما تؤئز سلبيا على دقة الأداء المهاري.

وان القوة هي أحد أهم العناصر التي يسعى الرياضي الى تطويرها وذلك لان نطور القوة يعني تطور ادائه الحركي وخاصتا في لعبة الإسكواش لان اللعب السريع والمجه يتطلب قوة كبيرة لأستمرار اللاعب في نفس الوتيره لذلك لك لهي يسعى الرياضي الىى نطوير قوته كي يحسن من أدائه الحركي طبقا لفنون اللعب وتكنيكها (27:6)، وأن القوه العضلية هي صفة أساسية تلعب دور كبير بين الصفات البدنية ولها أهية كبيرة في النشاط الرياضي وخاصنا في لعبة الإسكواش، فأرتباط القوة بالسرعة هي عبارة عن أكساب الجسم صفة مميزة في الأداء الحركي هو القوة الأنفارية،(63:7) أما المرونة في ضوء التطبيق الأمتل للقوة خلال الزواية الملائمة للحركة بما يتتاسب مع ما يحتاجة الأداء الفني المحدد وخاصتا في لعبة الإسكواش اذ تتطلب مرونة عالية وذلك بسبب اللعب السريع وان المرونة تقاس بادرجات او الزاويات الدائرية او السنتيمتر (297:8).

ويرى الباحثان يجب نطوير الصفات البدنية ولا سيم (القوة والمرونة) ليتم تطوير صفة الدقة للاعب عن اداء

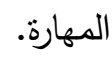

ع - المبحث الرابع: الأستتاجات والتوصيات.

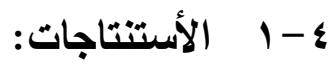

• تنين ان هنالك ضعف في القوة والمرونة والدقة لدى اللاعبين

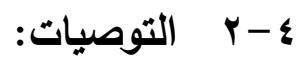

• أعداد منهاج تدريبي لتطوير القدرات البدنية (القوة والمرونة).

• أعداد منهاج تدريبي لتطوير دقة الأداء المهاري.

• تصميم جهاز مقترح لتطوير الدقة لدى اللاعبين.

• أستخدام أدوات مساعدة جديدة لنطوير صفة القوة والمرونة وكذلك لتطوير الدقة لدى اللاعبين. 
مجلة كلية التربية الرياضية - جامعة بغداد ** المجلد الثلاثون ** العدد الثاني * لسنة $r \cdot 11$

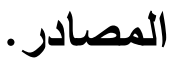

1. محمد صبحي حسانين، القياس والتقويم في التربية الرياضية، جا، (القاهرة، دار الفكر العربي، 990 (1).

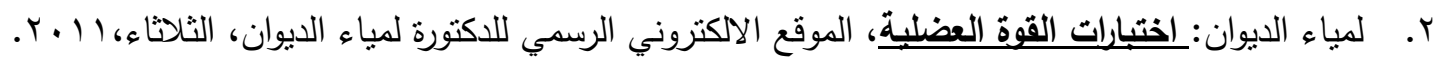
r. محمد شعر الدين واحمد متولي منصور : 9 9 تمريناً للقوة العضلبة والمرونة الحركية لجميع الانشطة الرياضبة. مركز الكتاب للنشر، طا.

4. ITF TENNIS.com: International tennis federation, science \& medicine, 2017. http://www.itftennis.com/scienceandmedicine

ه. ياسر وجيه قدوري: تأثير تمرينات خاصة في تطوير القدرات التوافقية والكتغيرات البيوميكانيكية ودقة الضريات الأرضية الأمامية والخلفية للاعبي الإسكواش والتنس تحت 19 ينة، أطروحة دكتورا، كلية التربية البدنية وعلوم الرياضة - جامعة بغداد، سنة 2017.

7. كمال جميل الريضي: التدريب الرياضي للقن الواحـ والعشرين، ط2، دار وائل للنشر والتوزيع ، عمان، سنة .2004

V. محمد عبد الحسن: علم التّريب الرياضي ل111، ط1، مكتبة الأبتكار للطباعة، سنة 2010. ^. محمد أبراهيم شحاته: أساسبات التدريب الرياضي، المكتبة المصرية للطباعة والنشر ، سنة 2006. 